\title{
Outbreak and Eradication of Tropical Rat Mite (Acari: Macronyssidae) in a European Animal Facility
}

\author{
Yeray Brito-Casillas, ${ }^{1,2,6}$ Mercedes Díaz-Sarmiento, ${ }^{1,3}$ Moisés García-Arencibia, ${ }^{1}$ \\ Cristina Carranza, ${ }^{1,4}$ Antonio Castrillo, ${ }^{1,3}$ Leandro Fernández-Pérez, ${ }^{1}$ Manuel Zumbado- \\ Peña, ${ }^{1}$ Jorge F. González, ${ }^{2,5}$ and Ana M. Wägner ${ }^{1}$
}

\begin{abstract}
'Instituto Universitario de Investigaciones Biomédicas y Sanitarias de la Universidad de Las Palmas de Gran Canaria (IUIBS-ULPGC), Las Palmas De Gran Canaria, Canarias 35016, Spain, ${ }^{2}$ Servicio General de Investigación Animalario Experimental de la Universidad de Las Palmas de Gran Canaria (SGIAE-ULPGC), Arucas, Canarias 35413, Spain, ${ }^{3}$ Instituto de Investigaciones Biomédicas Alberto Sols de Madrid, Consejo Superior de Investigaciones Cientificas (CSIC), 28029 Madrid, Spain, ${ }^{4}$ Unidad de Enfermedades Infecciosas y Medicina Tropical, Complejo Hospitalario Universitario Insular Materno Infantil de Gran Canaria (CHUIMI), Las Palmas De Gran Canaria, Canarias 35013, Spain, ${ }^{5}$ Departamento de Patología Animal, Facultad de Veterinaria, ULPGC, Arucas, 35413 Canarias, Spain, and ${ }^{6}$ Corresponding author, e-mail: yeray.brito@fpct.ulpgc.es
\end{abstract}

Subject Editor: David Florin

Received 23 March 2017; Editorial decision 22 August 2017

\begin{abstract}
A zoonotic, opportunistic out-break of tropical rat mite Ornithonyssus bacoti [Acari: Macronyssidae; Ornithonyssus bacoti (Hirst)] in an animal facility, is described. Immunocompetent mice [Mus musculus (Linnaeus)] and rat [Rattus norvegicus (Berkenhout)] strains in a conventional health status facility suffered from scratching and allopecia and staff members suffered from pruritic, erythemato-papular lesions, presumed to be allergic in origin. $O$. bacoti was identified and treatment with a $0.1 \%$ ivermectin solution led to its complete erradication. Safety assessment revealed no signs of acute toxicity in any animal strain. Following this inexpensive strategy, 7 wk after the initial dose, samples were negative for the presence of acari. At the time of this report, 26 months after diagnosis, 0 . bacoti remains undetected.
\end{abstract}

Key words: dermatitis, Macronyssidae, mouse, Ornithonyssus bacoti, zoonosis

Immunocompetent, inbred strains of Sprague Dawley rats, C57Bl/6J and $\mathrm{BALB} / \mathrm{c}$ mice, and $\mathrm{C} 57 \mathrm{Bl} / 6 \mathrm{~J}$ background transgenic mice [B6;129S4-Pcmt1 ${ }^{\text {tm1Scl }}$ (Pcmt1 $\left.{ }^{+-}\right)$, C57Bl/6-Socs2 $2^{\text {tm1Wehi }}$ (Socs2-l-), $129 \mathrm{~S} / \mathrm{SvEv}-\mathrm{Nr} 1 \mathrm{~h} 3^{\mathrm{tm} 1.1 \mathrm{Djm}-/-} \quad\left(L X R \alpha^{--}\right), \quad 129 \mathrm{~S} / \mathrm{SvEv}-\mathrm{Nr} 1 \mathrm{~h} 2^{\mathrm{tm} 1.1 \mathrm{Djm}}$ $\left(L X R \beta^{-1-}\right), \quad L X R \alpha \beta^{-1-}$ obtained by intercrossing $129 \mathrm{~S} / \mathrm{SvEv}_{\mathrm{Ev}}$ $N r 1 h 3^{\mathrm{tm} 1.1 \mathrm{Djm}-/} \times 129 \mathrm{~S} / \mathrm{SvEv}-\mathrm{N} r 1 h 2^{\mathrm{tm} 1.1 \mathrm{Djm}}, \mathrm{B} 6 ; 129 \mathrm{~S} / \mathrm{SvEv}-\mathrm{Bcl} 2112 /$ IRF3 $^{\text {tm1Ttg }}\left(\right.$ IRF3 $\left.^{--}\right)$] developed scratching and dorsal and back alopecia that in severe cases co-existed with weight-loss and wounds (Fig. 1A and B). Litters of $I R F 3^{--}$mice showed petequiae over the whole body (Fig. 1C). Initially, only mild isolated cases were detected, but within $1 \mathrm{wk}$, scratching was generalized in the rodent colonies within the facility. Simultaneous to the findings in the mice, four of the five regular animal care technicians and three researchers developed pruritic, erythemato-papular lesions (1-3 cm), located on knees, hips, abdomen, chest, neck, and forearms (Fig. 1D). Later, direct examination of the cages revealed oval mites that moved fast around and from animals to bedding (Fig. 2A). In one severe case, we observed adult mites in the fur (Fig. 2B). In order to immediately control this zoonotic outbreak, we used available diagnostic tools and treatments.

\section{Materials and Methods}

This facility belongs to the Faculty of Health Sciences of the University of Las Palmas de Gran Canaria, in The Canary Islands, Spain. It is maintained under conventional health conditions (temperature: $23 \pm 3^{\circ} \mathrm{C}$; relative humidity $60 \pm 5 \% ; 12: 12 \mathrm{~h}$ dark:light cycle). Water is directly administered from the public supply and the standard diet of the rodents is 2018 Teklad Global Diet (Harlan Laboratories). This research colony comprises $\sim 1000$ cages (120260 cages per room, six rooms total), with $100 \%$ of the rats and $75 \%$ of the mice allocated in open, makrolon cages, and the rest in isolated, ventilated cages (Allentown Caging Equipment, $\mathrm{NJ}$ ). Poplar woodchips were used as bedding (Lignocel Select Fine, Rettenmaier \& Söhne, Rosenberg, Germany) with mouse houses and paper provided as environmental enrichment. Personnel entering the facility wear a specific protective clothing or lab coat, gloves, masks, and head covers. No personnel had pet rodents at home. One of the staff members was diagnosed of allergic lesions by a physician and antihistamines was prescribed, although blood tests were negative. Medical treatment of personnel is confidential and thus is 


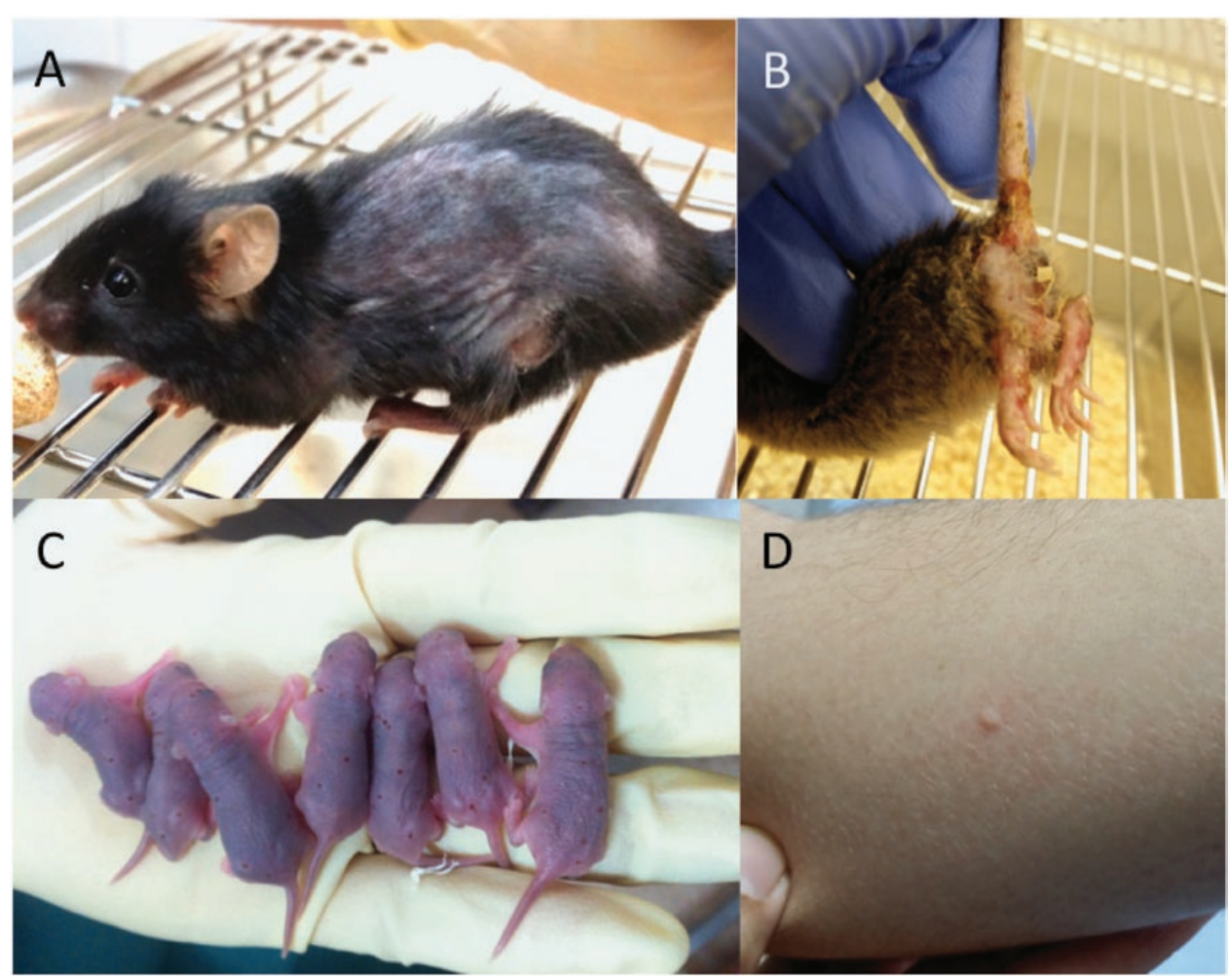

Fig. 1. Clinical findings in animals and personnel. Different degrees of scratching, wounds, and weight-loss were observed in the whole colony: 6 -wk C57BI/6J female and 18-wk LXR $\alpha \beta^{-/-}$male, showing severe manifestations with ulcers (A and B). Lessions resembling petequiae in 5-day IRF3 $3^{--}$litter (C). Pruritic papulae on the forearm of an animal technician (D).

not addressed in this report. To our knowledge, no prick test was performed. The symptons had started 3-5 wk before diagnosis and appeared periodically, in relation with the working hours. They took place at the beginning of the working period, lasting hours, with different intensity among individuals. No family members of the staff showed any symptons.

To assess the extent of the infestation, adhesive traps were distributed (2-4 cages/rack, 6-24 cages/room; $5-10 \%$ of the maximum capacity of cages per rack or room) in all of the rooms of the facility, and hair samples from two animals per room were examined by sticking tape onto their fur $(0.5-2 \%$ of mice per room) (Conole et al. 2003). Tape was also stuck to the floor and walls of $2-4$ cages/room, after removing the bedding before cleaning. Finally, two animals per room were sacrifized (isofluorane overdose) for deeper examination, including scalpel skin scrapes from the head, back, and ventrum (Ricart Arbona et al. 2010). Their carcasses were inserted in a 50-ml tube (Biologix Group Ltd., PR. China) and left at $4^{\circ} \mathrm{C}$ overnight. Subsequently, fur was again sampled from neck, back, and ventrum; contents were transferred from tube to tape. Samples were affixed to glass slides and examined microscopically at $100 \times$ and $200 \times$ following a grid pattern.

Sprayed $0.1 \%$ ivermectin was chosen as the method of treatment (Baumans et al. 1988a, 1988b) for the rodent colonies. Vectimax $10 \mathrm{mg} / \mathrm{ml}$ (ECO Animal Health Ltd., Surrey, United Kingdom) was diluted 1:100 in a solution of propyleneglycol (Panreac Quimica SLU, Barcelona, Spain) and distilled water (1:1). The volume of solution sprinkled with hand held sprayers (total volume of $500 \mathrm{ml}$ ) at 0.2-0.5 $\mathrm{m}$ distance of the bedding (Baumans et al. 1988b), ranged $1-1.5 \mathrm{ml}$ (0.5 ml per spray), and a maximum of $0.5 \mathrm{ml}$ over the animals, as spraying was adapted ad hoc to their size. The sprinkled volume was determined by direct spraying into $2 \mathrm{ml}$ microtubes
(Sarstedt AG \& Co, Nümbrecht, Germany) and directly measured with a pipette ( $m 1000$, Biohit, Biohit Oyj, Helsinki, Finland). The estimated dose of topical ivermectin per animal was lower than $0.5 \mathrm{mg}$. In rats, 2-3 sprays per animal were applied, following the same criteria. The validity of the treatment was tested when 10-20 adult mites were inserted into a 2-ml microtube (Sarstedt AG \& Co) and $2.5 \mu \mathrm{l}$ of the treatment was added at the bottom. To test ivermectin's acute toxicity in all strains, cages with $2-5$ adult animals per strain were sprayed. Given the urge to treat and reduce the parasite load, only a $24 \mathrm{~h}$ evaluation was performed, based on direct examination at different time points.

Afterwards, the whole colony was sprayed, with the exception of breeders, where only bedding and males were sprayed, and litters close to weaning, where only the mothers received the treatment (Lankas et al. 1989). Re-treatment was performed twice, on a weekly basis, in the whole colony.

Frequency in the regular cleaning of cages, racks, and rooms was increased from biweekly to weekly. Immediately after cleaning, cages were also sprayed with the ivermectin solution.

The diagnostic and treatment procedures were not subject to review by an animal welfare committee, in accordance with Directive 2010/63/UE, Articles 3.1 and 1.5, since they were considered to be clinical interventions.

\section{Results}

Acariasis was confirmed following microscopic evaluation, with the subject mites morphologically identified as Ornithonyssus bacoti (Hirst) (Acari: Macronyssidae) by the Infectious Diseases and Tropical Medicine Unit within the hospital (Fig. 2C and D) (Watson 2008). All rooms were infested, although parasitic loads varied. 


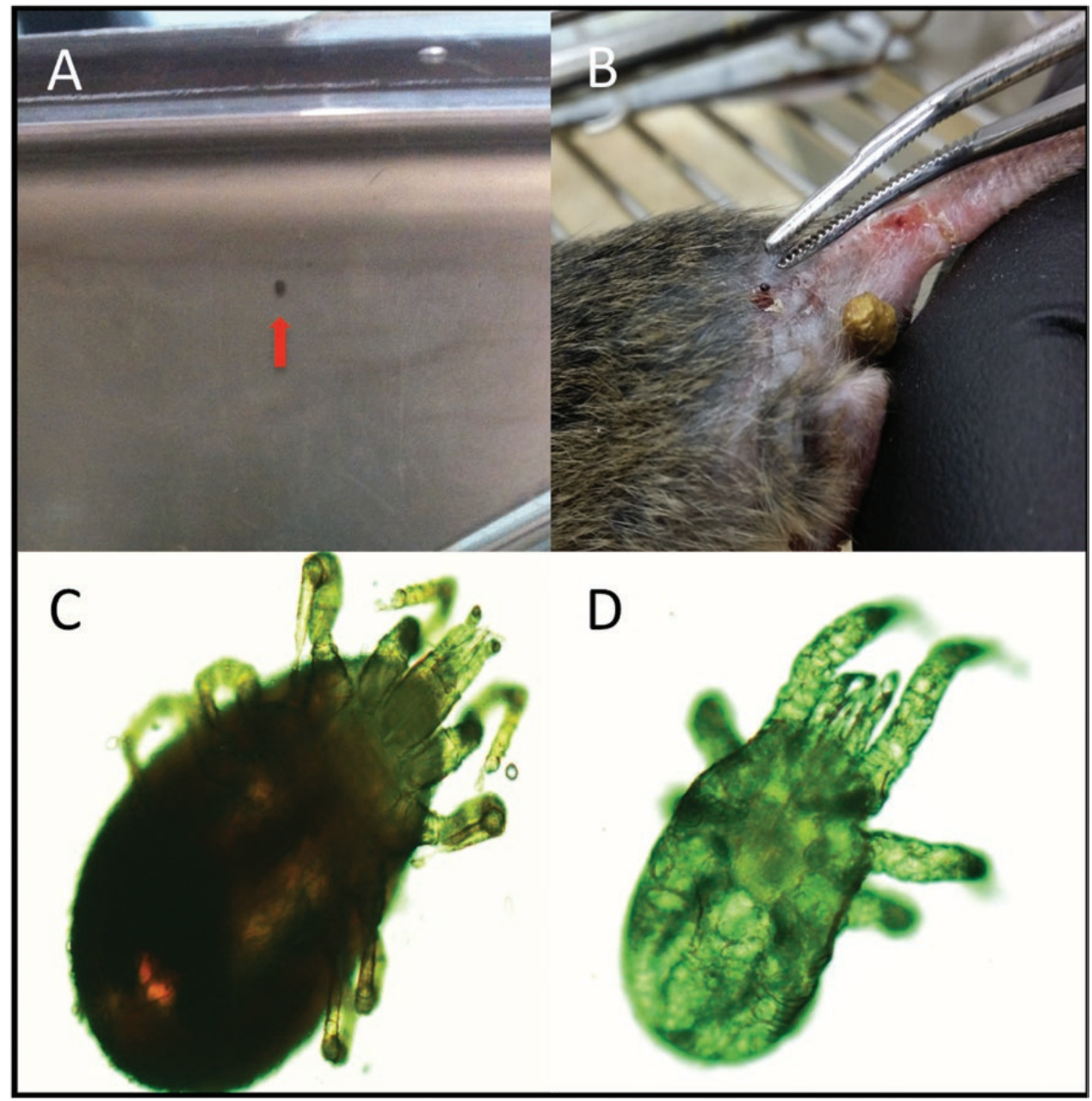

Fig. 2. Diagnosis by direct and microscope observation. Initially, adult mites were directly observed in the cages (1-2 mm in length, red when they are blood fed), in certain occasions walking on the cage's sides (A). An adult, haematophagous parasite, is shown in a severe case (B). Diagnosis and extension of the parasitosis were confirmed following fur and carcass evaluations in $50 \mathrm{ml}$ tubes; $\mathrm{O}$. bacoti was microscopically identified (C and D: dorsal view of two adults of O. bacoti, 100× magnification).

Adult mites and juvenile forms were detected in different proportion by each diagnostic method (parasite morphological stage [range]) (two forms detected [0-14]), postmortem analysis being the most efficient (1.25 forms detected [0-9]). Before treatment, 4 mite forms [0-14] were counted per sampled slide. Infestation was re-assessed at three, 14 and $21 \mathrm{~d}$ after each treatment, following the diagnostic process described above. The number of positive slides was sharply reduced to 1 mite per slide [0-4] just 1 wk after treatment, immediately before the second application. Fourteen days after initial application, median count remained at 1 mite form per slide [0-2]. During this period, the percentage of negative slides rose from $8 \%$ before treatment, to 14,50 , and $100 \%$ during the subsequent weeks. Finally, a total of three treatments were administered in all rooms of the whole colony. All sampled slides continued to be negative $28 \mathrm{~d}$ after first treatment.

The most extensively infested were $\mathrm{LXR} \alpha \beta^{-- \text {, }}$ IRF3 $3^{--}$, and $\mathrm{SOCS}^{-/-}$mice. Previous, annual health controls of the facility had never reported any acari.

During the treatment evaluation, following the described validity test, immediate death was observed for most acari and none survived a $12 \mathrm{~h}$-exposition period. No evident clinical signs were neither observed during the acute toxicity evaluation nor weeks later.

\section{Discussion}

O. bacoti, also known as the Tropical rat mite, is a parasitic mite of the genus Macronyssidae found on many rodent species (Kelaher et al. 2005). Size ranges from 0.75 to $1.4 \mathrm{~mm}$, it is haematophagous, and infestations represent a serious problem for any animal facility (Cole et al. 2005, Kelaher et al. 2005, Watson 2008, Cafiero et al. 2011).

Dermatitis, scratching, weight loss, and reduction in the number of litters represent main clinical manifestations, but the mite species can also act as a vector of pathogens from wild rodents, such as the filarial worm Litomosoides sigmodontis (Renz and Wenk 1981), that also transmits Hepatozoon muris (Watson 2008). Different experimental studies and reports have shown O. bacoti to be a vector for Rickettsia, Yersinia pestis, or Bartonella, among others (Cole et al. 2005).

O. bacoti has a global distribution (Engel et al. 1998), including continental Spain (Rosa et al. 2014), but to our knowledge there are no reports of its presence in the Canary Islands. Regarding zoonotic episodes, there is only one recent report in continental Spain (Rosa et al. 2014) and sporadic documentations in the rest of Europe (Engel et al. 1998, Beck and Folster-Holst 2009, Cafiero et al. 2011). 
There has only been one previous infestation in a European animal facility (Cafiero et al. 2011).

O. bacoti disperses hundreds of meters to find new vertebrate reservoirs when upon the death of a host and infestations have been related to building construction when commensal colonies of rodents were disturbed (Watson 2008). At the time of the outbreak, construction and fumigations were taking place in the building that houses the rodent colony. Presumably, when the infested wild rodents died, their parasites moved to new hosts among the rodent colony.

The life cycle of $O$. bacoti can be completed in 6-8 $\mathrm{d}$ and females live up to 70, laying 90-140 eggs in the environment just 2-3 d after a single bloodmeal (Cole et al. 2005, Watson 2008, Beck and FolsterHolst 2009). This high prolificity and persistence in the environment accelerate its expansion and makes eradication difficult.

Previous treatments to eradicate O. bacoti from animal research facilities were mostly based on insecticides (pyrethrins and pyrethroids), as well as fluoridated silica aerogel or sylamectin (Cole et al. 2005, Kelaher et al. 2005, Watson 2008, Rosa et al. 2014). Insecticides were ruled out in this case, since they are not recommended in animal facilities for safety concerns (Watson 2008).

Ivermectin demonstrated high effectiveness in rodents, as it shows a versatile administration (sprayed, spot-on, and/or orally) (Baumans et al. 1988a, 1988b; Watson 2008), and it represents a good option to treat this parasite. The safety of the drug was assessed acutely only, as treatment was necessary immediately. A more thorough and comprehensive evaluation is recommended before treatment, especially for transgenic rodent strains (Davis et al. 1999, Elmquist and Miller 2001). Toxicity has been described after chronic systemic administration to rodents, but there is some controversy about outcome and harmful dose (Lankas et al. 1989, Davis et al. 1999, Ricart Arbona et al. 2010). Undesired effects include behavioural changes, weightloss, growth delay, and neonatal mortality (Lankas et al. 1989, Davis et al. 1999, Ricart Arbona et al. 2010), but none was observed in the present case. Moreover, previous publications with sprayed ivermectin did not indicate toxic effects (Baumans et al. 1988a), even though the dose was double from what was used in our control measure.

After the eradication of $O$. bacoti from the facility, all the lesions disappeared in the employees and users of the animal facility, too. Confusion between parasitic papulae and allergy is common and the definite diagnosis is frequently established by direct parasite detection (Beck and Folster-Holst 2009). We agree with other authors regarding the importance of active collaboration between veterinarians and physicians in animal facilities (Watson 2008, Beck and Folster-Holst 2009, Cafiero et al. 2011).

Although the risk of O. bacoti infestations is low, its global distribution and high mobility and prolificity make it a potential intruder to any facility, regardless of its sanitary barriers. We believe that the present report could be helpful in future O. bacoti outbreaks.

\section{Acknowledgments}

We are grateful to Jose Luís Martín Barrasa, Clara Muñoz Mediavilla, and María Jesús Molina Cimedavilla for their professional advice and Natalia María Santana and Francisco Martín González for their commitment in the care of the animals.

\section{References Cited}

Baumans, V., R. Havenaar, and H. van Herck. 1988a. The use of repeated treatment with Ivomec and Neguvon spray in the control of murine fur mites and oxyurid worms. Lab. Anim. 22: 246-249.

Baumans, V., R. Havenaar, H. van Herck, and T. P. Rooymans. 1988b. The effectiveness of Ivomec and Neguvon in the control of murine mites. Lab. Anim. 22: 243-245.

Beck, W., and R. Folster-Holst. 2009. Tropical rat mites (Ornithonyssus bacoti) - serious ectoparasites. J. Dtsch Dermatol. Ges. 7: 667-670.

Cafiero, M. A., Galante, D., Cavaliere, N., Nardella La Porta, C., Caiazzo, M., Lomuto, M. Year. Published. Occupational outbreak of tropical rat mite (Ornithonyssus bacoti) dermatitis in laboratory personnel, in southern Italy (Apulia region). In, 21st ECCMID-27th ICC Congress, 7-10 May 2011, Milan. Clinical Microbiology and Infections.

Cole, J. S., M. Sabol-Jones, B. Karolewski, and T. Byford. 2005. Ornithonyssus bacoti infestation and elimination from a mouse colony. Contemp. Top. Lab. Anim. Sci. 44: 27-30.

Conole, J., M. J. Wilkinson, and Q. A. McKellar. 2003. Some observations on the pharmacological properties of ivermectin during treatment of a mite infestation in mice. Contemp. Top. Lab. Anim. Sci. 42: 42-45.

Davis, J. A., R. Paylor, M. P. McDonald, M. Libbey, A. Ligler, K. Bryant, and J. N. Crawley. 1999. Behavioral effects of ivermectin in mice. Lab. Anim. Sci. 49: 288-296.

Elmquist, W. F., and D. W. Miller. 2001. The use of transgenic mice in pharmacokinetic and pharmacodynamic studies. J. Pharm. Sci. 90: 422-435.

Engel, P. M., J. Welzel, M. Maass, U. Schramm, and H. H. Wolff. 1998. Tropical rat mite dermatitis: case report and review. Clin. Infect. Dis. 27: 1465-1469.

Kelaher, J., R. Jogi, and R. Katta. 2005. An outbreak of rat mite dermatitis in an animal research facility. Cutis 75: 282-286.

Lankas, G. R., D. H. Minsker, and R. T. Robertson. 1989. Effects of ivermectin on reproduction and neonatal toxicity in rats. Food Chem. Toxicol. 27: 523-529.

Renz, A., and P. Wenk. 1981. Intracellular development of the cotton-rat filaria Litomosoides carinii in the vector mite Ornithonyssus bacoti. Trans. R. Soc. Trop. Med. Hyg. 75: 166-168.

Ricart Arbona, R. J., N. S. Lipman, E. R. Riedel, and F. R. Wolf. 2010. Treatment and eradication of murine fur mites: I. Toxicologic evaluation of ivermectin-compounded feed. J. Am. Assoc. Lab. Anim. Sci. 49: $564-570$.

Rosa, C., J. Castellà, and J. Martorell. 2014. First record of Ornithonyssus bacoti from pet hamsters as cause of zoonosis in Spain. Clín. Vet. Pequeños Anim. 34: 207-210.

Watson, J. 2008. New building, old parasite: mesostigmatid mites - an everpresent threat to barrier facilities. ILAR J. 49: 303-309. 